\title{
Inserted During a Procedure but Prior to Percutaneous Coronary Intervention
}

National Cancer Institute

\section{Source}

National Cancer Institute. Inserted During a Procedure but Prior to Percutaneous

Coronary Intervention. NCI Thesaurus. Code C99963.

Mechanical Circulatory Support was inserted during the procedure. (ACC) 